\title{
REGIONÁLNÍ GASTRONOMIE V MORAVSKOSLEZSKÉM KRAJI JAKO PROSTŕ EDEK PRO PODPORU CESTOVNÍHO RUCHU
}

\section{REGIONAL GASTRONOMY AS A MEANS TO PROMOTE TOURISM IN THE MORA VIAN-SILESIAN REGION}

\section{DOC. PAedDr. Peter LUKA, PhD.}

\section{Mgr. Klára VÁCLAVÍNKOVÁ}

\author{
Katedra cestovního ruchu $\mid$ Department of Tourism \\ Obchodn クpodnikatelská fakulta v Karviné The School of Business Administration in Karvina \\ Slezská univerzita v Opav $\rceil$ Silesian University in Opava \\ $\triangle$ Univerzitní nám $\eta_{\text {tí }}$ 1934/3, 73340 Karviná, Czech Republic \\ E-mail: cuka@opf.slu.cz,vaclavinkova@opf.slu.cz
}

\begin{abstract}
Anotace
Cílem $p$ Śisp \łku je vyty! it základní $p$ Śedpoklady v regionu pro regionální gastronomii a zhodnotit tak, zda je v Moravskoslezském kraji moǵnost tento smn rozvijet a podpoŚit tak cestovní ruch. L̦lánek pracuje s metodami SWOT analýza a regionální analýza. Vúvodu jsou vnovány kapitoly teoretickým výstup $\coprod m$. V praktické !ásti následuje zhodnocení potenciálu oblasti pro cestovní ruch. Na základП provedené regionální analýzy, která byla zam గśena na popis geografických, demografických a kulturních pŚedpokladT oblasti, $m$ Tógeme hovoŚt o tom, ǵe Moravskoslezský kraj má pŚedpoklady pro rozvoj regionální gastronomie.
\end{abstract}

Klị́̂vá slova

cestovní ruch, gastronomie, Moravskoslezský kraj

\section{Annotation}

The aim of this paper is to set out the basic prerequisites in the region for regional gastronomy and evaluate as to whether the Moravian-Silesian Region the opportunity to develop this direction and encourage tourism. Article works with methods SWOT analysis and regional analysis. In the beginning chapters are devoted to the theoretical output. In the practical part follows the appreciation potential of the area for tourism. Based on the regional analysis, which focused on the description of geographic, demographic and cultural assumptions of the field, we can talk about the MoravianSilesian region has potential for the development of regional gastronomy.

Key words

tourism, gastronomy, Moravian-Silesian Region

JEL classification: $L 83$

\section{Úvod}

Regionální gastronomie patŚ $\mathrm{k}$ trendTm soul asné doby. PatŚ mezi moǵnosti podpory cestovního ruchu v oblasti. AutoŚ se pokusí v lٕlánku popsat pŚedpoklady Moravskoslezského kraje pro rozvoj regionální gastronomie jako prostŚedku pro podporu cestovního ruchu v oblasti. Metody budou pougoity regionální analýza a SWOT analýza. Cílem pŚsph $\mathrm{ku}$ je vytỵ̣ it základní pŚdpoklady $\mathrm{v}$ regionu pro regionální gastronomii a zhodnotit tak, zda je v Moravskoslezském kraji moǵnost tento smlł rozvíjet a podpoŚt tak cestovní ruch. 


\section{Teoretické pSedpoklady}

\subsection{Regionální analýza}

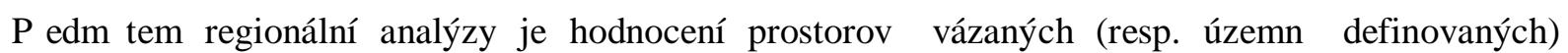
souborT dat o nejrTzn円ğch sociálnクekonomických, ale i fyzicko-geografických jevech !̣ i procesech. Jako blízké a spolupracující vhlní disciplíny lze pak uvést nejen socioekonomickou !̣ i fyzickou geografii, ale i geodemografii, regionální sociologii, sociální i krajinnou ekologii, sociální psychologii, historii a historickou demografii, kulturní antropologii, etnografii, politologii, územní plánování, urbanismus apod. (Hampl, 1998).

\section{Soul asné hlavní trendy a témata regionální analýzy}

V bhğných rutinních analýzách lze hovoŚt o ustáleném souboru pouğivaných kvantitativních metod a modelT. DTraz je pŚtom kladen na jejich promyg̉enou aplikaci, výbদ̆ a konstrukci vhodných ukazatelT s maximální rozliggovací a vypovídací schopností, validitu primárních dat, srovnatelnost ! asovou (=neexistence úplné |̣ asové shody konání národních cenzT | i mezinárodních sociologických getŚ́ní) a srovnatelnost v'cnou (=obsahovou, tj. sociokulturní, právní, klasifika!̣ ní, nesrovnatelnost

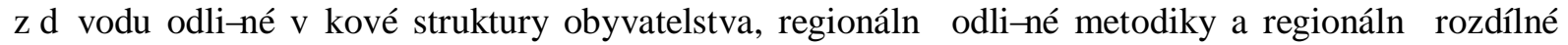
úsphónosti sbク̧u dat, resp. z dTvodu odlig̉ností evidovaného a nepodchyceného faktického stavu $\mathrm{v}$ jedné zemi apod.). V neposlední Śd円je kladen dTraz i na územní srovnatelnost pouǵivaných údajT (zmßny administrativních hranic, vznik VÚSC, NUTS, slu!̣ ování a osamostatRování obcí, rTzná popula! ní a plog̉ná velikost územních jednotek) (Bohál ková et al., 2009).

\section{Kritéria !̣lenクií regionální analýzy}

Terminologie spojená s ! len ḩím regionální analýzy na její jednotlivé typy a ḷ ásti je obvykle zaloǵena na tŚch vzájemnநodlig̣ných kritériích (Ivanil ka, 1998).

Lze charakterizovat regionální analýzu | lenit na |̣ tyŚ základní velké tématické oblasti, a to:

- regionální analýzu pŚrodních a ekologických podmínek území,

- regionální analýzu obyvatelstva, osídlení a sociálních podmínek,

- regionální analýzu ekonomických podmínek, dopravní a technické infrastruktury,

- analýzu regionálních vazeb a procesT.

\section{Hlavní pouǵ̛vané pŚstupy (typy) regionální analýzy}

Vg̉echny údaje, s nimiǵ regionální analýza pracuje, lze jednoduğe zaznamenat a znázornit buN̦ do podoby ! asoprostorové matice dat nebo matice prostorových interakcí a jejich $\mathrm{zm} h \mathrm{v}$ ! ase. $\mathrm{V}$ rámci kağdé $\mathrm{z}$ výǵe zmín円ných moǵných úrovní regionální analýzy (tj. internacionální, interregionální a intraregionální) lze uplatR̉ovat Śidu základních metodických pŚstup丁 (resp. typT analýzy), které mají odliğný cíl a vyugóivají obvykle i odlig̉né postupy, kvantitativní li i kvalitativní metody zpracování a odlig̉né jsou i jejich výstupy (verbální, kvantitativní, kartografické, grafické) (Hampl, 1998).

Komparativní pŚstup pŚedstavuje klasickou srovnávací analýzu (dvou nebo i více) územních jednotek. Jejím cílem je zjiğní míry podobnosti mezi územními jednotkami, a to jak na základクpodílových, strukturálních charakteristik, tak i na základク souborT jiných, rTznorodých, rTznク mrśených charakteristik. Zjiğnhá míra vzájemné podobnosti | i nepodobnosti územních jednotek mTǵe pak být podkladem pro tvorbu typologií a následné vymezování relativn円homogenních regionT (Bohál ková et al., 2009).

\subsection{SWOT analýza}

V rámci regionální analýzy lze pouǵ̛t Ămetoduñ tzv. SWOT analýzy. Tato motoda tvoŚ výjimku.

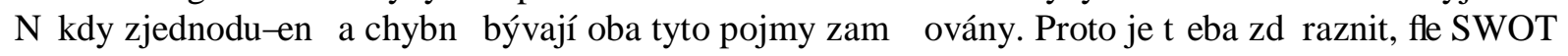


analýza pŚdstavuje pouze jeden z moğných pŚstupT analýzy regionální a ğe ï i pŚs jiǵ zağitý název Ănalýzañnejde o analýzu ve vlastním slova smyslu, ale spíge o jakousi syntézu díll ích analýz.

SWOT analýza je metoda, jejíǵ pomocí je moğno identifikovat silné (ang: Strengths) a slabé (ang: Weaknesses) stránky, pŚleğitosti (ang: Opportunities) a hrozby (ang: Threats), spojené s ur!̣ itým projektem, typem podnikání, podnikatelským zám円em, politikou (ve smyslu opatŚní) apod. Jedná se o metodu analýzy uğivanou pŚedevğm v marketingu, ale také napŚ pŚ analýze a tvorbクpolitik (policy analysis). Díky tomu je moǵné komplexnךvyhodnotit fungování firmy, nalézt problémy nebo nové moǵnosti rTstu. Je souḷ ástí strategického (dlouhodobého) plánování spoleḷ nosti (Jakubíková, 2009).

Jako její hlavní pŚdnost bývá uvádhna názornost, pŚ́hlednost, výstiğnost, jednoduchost a strul nost.

Dle Bohma (2008) její název vznikl jako zkratka ze !̣ tyŚanglických slov, a to:

S ï strong, strenghts - silné stránky, klady, pŚednosti daného území,

W ï weak, weaknesses - slabé stránky, zápory, nedostatky, limity, nerovnováhy

$\mathrm{O}$ - opportunities - pŚleǵitossti, moǵnosti rozvoje a ğnce ovlivnnhé a podmínhné zvnクg̉ku,

$\mathrm{T}$ - threats - rizika, hrozby, potenciální ohroğení pŚcházející zvenku.

Výstupem této metody je souhrn krátkých, výstióných konstatování (pojmenovaných skutel ností !̣i faktorT), která jsou uspoŚídána do pśshledné struktury ! tyŚblokT, pólT! i kvadrantT, tzn. výstupem je schéma mající obvykle následující podobu:

\begin{tabular}{|c|c|c|c|c|}
\hline S & $\mathrm{W}$ & Silné stránky & Slabé stránky & S+W vnitŚní faktory (Mise) \\
\hline $\mathrm{O}$ & $\mathrm{T}$ & Moǵnosti & Hrozby & O+T vnクg் faktory (Vize) \\
\hline
\end{tabular}

\section{Krajová a regionální gastronomie}

\section{Definice kulináŚského turismu (culinary tourism)}

KulináŚký turismus je relativnク mladá oblast cestovního ruchu. Jako samostatné odvクví zaḷal fungovat aǵ v roce 2001 a teprve $\mathrm{v}$ roce 2003 zaloğil Erik Wolf International Culinary Tourism Association. PŚsto je dnes odvクvím velice dTleǵitým a jeho význam stále roste. Specialty Travel Agents Association dokonce oznaḷ ila kulináŚsḱ turismus za trend I. 1 v cestovním ruchu pro rok 2009. KulináŚsý turismus je definován jako cestování za unikátními a pozoruhodnými kulináśsými zkuġenostmi vğeho druhu. Mnoho lidí si sice myslí, ǵe kulináŚký turismus znamená objíǵdh

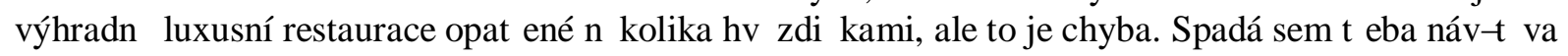
stánku na ulici v Pekingu, baru v zastr! ené uli! ce New Yorku, o kterém vhlí jen místní, nebo i vychutnání si zmrzliny na ulici kdesi v Itálii. Jiǵ prTzkum provedený pక́ed pár lety pro World Travel Market v Londýnク ukázal, ǵe z 2000 dotazovaných celých 53 procent povaǵuje pojídání tradil ních místních pokrmT za velmi dThleğitou soul ást své dovolené. KulináŚské dovolené jsou dnes brớné po

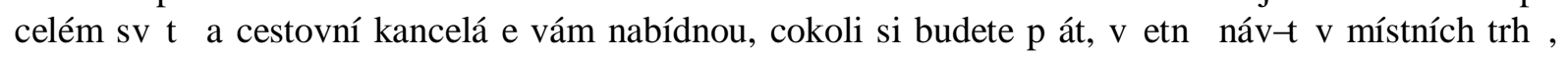
lekcí vaŚní a ochutnávek vğeho moğného (Krizek et al., 2011). KulináŚsé turismus je definován jako výkon jedinel ného a nezapomenutelného stravování a pití. Je zamłśsen na vyhledávání a poǵivání z pŚpraveného jídla a nápojT. Nelze jej zaŚsidit jako formu agroturistiky (Jakubíková, 2012).

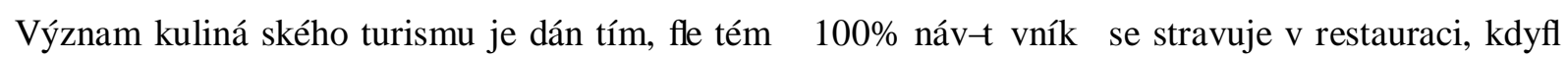
cestuje. Je to pŚleǵitost poznat místní jídlo a kulturu v destinaci. V soul asnosti lze Ści, ǵe místní kuchynクje motival ní faktor pŚ výbク̧u destinace.

Zájem o kulináŚký cestovní ruch není vyhrazen konkrétním vnkem, pohlavím, nebo národností. Turisté kulináŚsého cestování se také zajímají o muzea, nakupování, umßní a rekreací a jsou vysoce motivováni k získání zkuggeností z jedinel ného a nezapomenutelného stravování.

\section{Projekt Ochutnejte Leskou republiku}

Tento projekt byl zaloǵen ve spolupráci Czechtourism, Asociací hotelT a restaurací L̦eské republiky a Asociací kuchaŚ a cukráŚ ! eské Republiky. Cílem tohoto projektu je návrat ! eské gastronomie do nağch restaurací a pŚdstavit tak regiony z pohledu kulináŚkých a jedinel ných specialit z okolí. Restaurace jsou oznal eni logem Czech Specials a v nabídce thchto restaurací turisté naleznou národní 
pokrmy jako napŚklad svíl kovou anebo koprovku a dále pak minimálnךjeden pokrm, který je typický pro url itý region. Lze uvést napŚklad kapŚ hranolky typické pro Jiǵní Ḷechy anebo krkonoġké

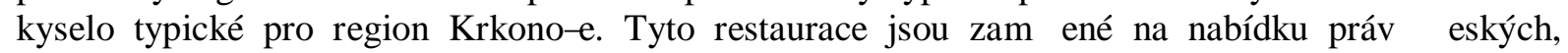
moravských a slezských specialit. Mezi restaurace, které jsou certifikované logem Czech Specials, patŚ napŚklad v Praze: Restaurace u l erného orla, síŠrestaurací Potrefená Husa, Park Holiday, Café Imperial. Dále to jsou restaurace, které se nacházejí po celé L̦ eské republice, napŚklad mTǵeme najít takovou restauraci v Mariánských Lázních (ChurchillŜ Pub \& restaurant), v Ḷeských Bud円ovících (Metropol, Potrefená Husa), v Plzni (Pivnice Belvedere, restaurace Purkministr) a mnoho dalğch (CzechTourism, 2014).

\section{Stezky dß̧lictví ï tradiḷ ní l̦ eská gastronomie}

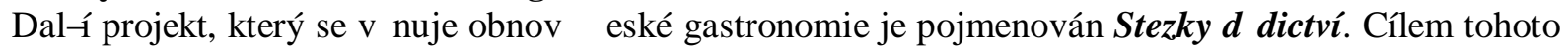
projektu je nabídnout domácím a zahranil ním návğĐyníkTm nejlepg̛ záǵitky z regionální gastronomie. Stezky dhdictví jsou uskutel Ŕovány spoleḷ ností ECEAT (European Centre for Ecological and Agricultural Tourism) a dalğmi partnery. V soul asnosti se projektu úl astní pŚs 70 restaurací, které se nacházejí na jiǵní Moravク Vysoḷ inךa v Praze. Restaurace, které splní url itá kritéria pro získání oznal ení ǍStezky dhlictvíñ jsou následnク zapsány do PrTvodce dobrými restauracemi. Mezi kritéria patŚ napŚklad následující body podnik musí nabízet minimálnり|tyŚ hlavní jídla regionální nebo l़ eské kuchynĐa jídla ani pŚlohy nejsou pŚpravovány z polotvarT.

Moravskoslezský kraj se snaǵi o propagaci regionální gastronomie a její vyuğití pro propagaci regionu. Na soukromé televizi Barandov brği poŚd : ĂJak ǵmakuje Moravskoslezskoña byla zároveŔ vydaná kuchaŚka stejného názvu.

Nejvýznamnクg் regionální speciality tohoto regionu jsou: bachora, Bylinný likér Lysá Hora, Oderský kapr, Gramberské ug̉, Klobásníky, Valaġké frgály, ř ízek Ondráǵ Pln円̧á husa se zelím a bramborovými knedlíky, Valaġká kyselica (Moravskoslezský kraj, 2014).

L̦lánek se bude zabývat pouze !̣astí regionální analýza a to posouzením pŚrodních a ekologických podmínek území. Bude popsána také demografický charakter území a hlavní parametry cestovního ruchu v oblasti. Poté budou vy! lenhyy silné a slabé stránky území, pŚleǵitosti a hrozby.

\section{Moravskoslezský kraj a jeho pSedpoklady pro cestovní ruch.}

\subsection{Regionální analýza}

\section{Geografické zal lenßí}

Následující ! ást se vhnuje geografickým, kulturním a demografickým charakteristikám dané oblasti. Bude taky popsán cestovní ruch v Moravsko-slezském kraji. Bude pracováno z daty z roku 2013, jedná se tedy o aktuální data.

Moravskoslezský kraj je geograficky velice rozmanitý region. Ze západu je sevŚn masívem Hrubého Jeseníku s nejvyğǵm vrcholem kraje a celé Moravy horou Pradhd (1 $491 \mathrm{~m} \mathrm{n}$. m.). Hornatina postupnク pŚchází do Nízkého Jeseníku, náhorní plog̉ny s pozvolnクğm terénem, a Oderských vrchT. StŚední !̣ ást kraje je charakteristická hust门osídleným nígínatým terénem Opavské níǵiny, Ostravské pánve a Moravské brány. Smクjem na jihovýchod krajina opク získává horský charakter a kulminuje hŚbety Beskyd ï u slovenské hranice Moravskoslezských s nejvyğğm vrcholem Lysou horou (1 $323 \mathrm{~m} \mathrm{n}$. m.) a Slezských Beskyd na hranici s Polskou republikou. Kraj leǵ na severovýchodநL eské republiky a tvoŚ jednu z nejvíce okrajových ḷástí. Na severu a východり hraniḷí s polskými vojvodstvími ï Slezským a Opolským, na jihovýchodり s G̣ilinským krajem na Slovensku. V rámci krajského uspoŚidání L̦R je lemován Olomouckým krajem a na jihu se letmo dotýká kraje Zlínského. PŚhranil ní charakter kraje poskytuje moǵnosti efektivní spolupráce ve výrobní sféś, rozvoji infrastruktury,

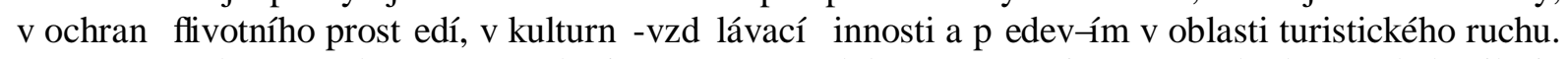
Za tímto úl elem pTsobí na území kraje v soul asné dobク4 euroregiony ï Beskydy, Pradhl, Silesia a Thönské Slezsko. 
Moravskoslezský kraj je vymezen okresy ï Bruntál, Frýdek-Místek, Karviná, Nový Jịlín, Opava a

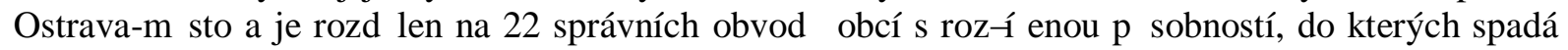
celkem 299 obcí, z toho je $41 \mathrm{~m}$ \$st. Svou rozlohou $5427 \mathrm{~km} 2$ zaujímá 6,9 \% území celé L ̣eské republiky a Śdí se tak na 6. místo mezi vg̉emi kraji. Více neǵ polovinu území kraje zaujímá zemদłınská $\mathrm{pTJda}$, na dalğch více neǵ $35 \%$ se rozprostírají lesní pozemky (pŚedevğm v horských oblastech JeseníkT a Beskyd). Vedle pŚrodního bohatství se v kraji vyskytují bohaté zásoby nerostných surovin ï pŚedevg̛̀m rozhodující domácí zásoby ! erného uhlí, dále loğiska zemního plynu a dalğch surovin jako jsou vápenec, ǵula, mramor, bŚdlice, sádrovec, ğhkopísky, písky a cihláŚké jíly (LL eský statistický úŚid, 2014a).

\section{Kultura a pŚdpoklady pro cestovní ruch.}

Tradil ními kulturními centry regionu jsou Ostrava, Opava a pro území Thğnska, s významnou polskou menğnou, LLeský Thğn. V kraji nalezneme velké mnoğství divadel, muzeí, galerií a kin.

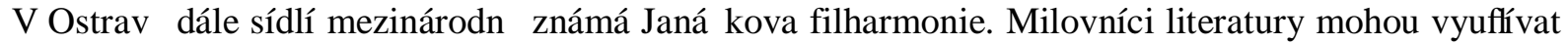
více neǵ 400 knihoven. Mḩta a obce nabízejí pestrou gkálu sportovního vyğití prostŚednictvím stadionT, víceúl elových hal a stovek hŚğš thocvil en, koupaliğš a bazénT. Kromり kulturního a sportovního vyğití ve $m$ ḩtech a obcích poskytuje malebná a pestrá pŚroda severní Moravy a Slezska nes! etné moǵnosti pro rekreaci, turistiku, poznávání kulturních památek a lél ebné pobyty. V letním období skýtá region díky rozsáhlé síti (cyklo)turistických tras podmínky pro prö turistiku a cykloturistiku, v zim pak jsou horské celky Hrubého Jeseníku a Beskydy vyhledávanými centry bhğeckého a sjezdového lyğ́ování. Moravskoslezský kraj se mTǵe pochlubit mnoha kulturními památkami, na jeho území se nachází m\$stské památkové rezervace (centra PŚbora, Nového Jị ína a Ġramberka). Zámeckými skvosty kraje jsou sídla v Hradci nad Moravicí, v Raduni, v KravaŚch na Opavsku !̣i ve Fulneku. Mezi nejvýznamnクğ hrady patŚ Sovinec na RýmaŚovsku, Starý Jị ín a Hukvaldy v Pobeskydí. Specifikem regionu jsou podmínky pro prTmyslovou turistiku (Technické muzeum automobilT v KopŚvnici, VagonáŚské muzeum ve Studénce, Hornické muzeum v Ostrav円PetŚkovicích, areál Dolních Vítkovic, NKP DT̄ Michal aj.). Fandové vodních sport] s oblibou sjíǵd円í Śku Moravici nebo Odru, ti, kteŚ dávají pŚdnost rekreaci u vodních ploch, navġhují nádrǵe G̦ermanice a Thlicko, v menğ míś zatím Slezskou Hartu. LázeŔství v kraji je zaloǵeno na vyuğití lél ebných úl inkT jodobromové vody v lázních Darkov s Rehabilital ním ústavem, od poḷ átku 90. let existuje nové lázeŔské sanatorium v Klimkovicích s architektonicky zajímavými budovami.

Dle L̦SU je v MSK aktuálnク 1225057 obyvatel, prTmクná hrubá mzda ! iní $22082 \mathrm{~K}$ ! a míra nezam ḩtnanosti je 9,65 \% (L eský statistický úŚd, 2014b). V souḷ asnosti jsou k dispozici i aktuální data týkající se cestovního ruchu. Regionální gastronomie je jeden z prostŚdkT pro propagaci oblasti. Je tedy potŚbné tyto data uvést. U návg̉hyník丁 p§́dpokládáme, ǵe se budou stravovat v restaurací a tvoŚ pak cílovou skupinu pro regionální gastronomii.

\section{Cestovní ruch v kraji}

Pol et pŚ́nocování host $\mathrm{v}$ hromadných ubytovacích zaŚzeních v Moravskoslezském kraji dosáhl v 2. ! tvrtletí 2013 tém敒400 tisíc a byl o 5,9\% niğǵ neǵ ve stejném období minulého roku. Tento úbytek zapŚ! inili rezidenti, u nichǵ dog̉o k meziro! nímu poklesu o $12,5 \%$, zatímco u nerezidentT byl trend opal ný ï nárȚst o 23,3\%. Z regionálního pohledu dog̉o k mezirol nímu nárTstu poḷ tu pŚenocování pouze ve ! tySech krajích republiky. O více neǵ jeden procentní bod tomu bylo v kraji Olomouckém (o 1,4 \%) a Zlínském (o 1,3 \%). Nejvýrazn円g் mezirol ní propad v poḷ tu pŚnocování zaznamenaly ubytovací zaŚzení v Královéhradeckém kraji o 12,1 \% a v Pardubickém kraji o 11,4 \%.

PrTmクnný poḷ et pŚenocování (2,6 nocí na jednoho hosta) Śdí kraj do stŚdu pomyslného krajského ǵebŚ! ku. Zcela bezkonkuren! ní místo zde zaujímá ẮázeŔskýñ Karlovarský kraj s poḷ tem 6,1 nocí. PrTmクnný poḷ et pŚ́nocování u rezidentT i nerezidentT je v Moravskoslezském kraji 2,6 nocí.

Ve 2. | tvrtletí 2013 pŚjelo do hromadných ubytovacích zaŚzení Moravskoslezského kraje 152140 hostT, z nichǵtémగśjjedna I tvrtina pŚjela ze zahranil í. Celkový pol et hostT je tak o 0,5\% niğǵ neǵ ve stejném období pŚedchozího roku. Zatímco poḷ et zahranil ních host se zvýğil o 8,0 \%, domácích 
hostT se v uplynulém ! tvrtletí ubytovalo o 2,9 \% ménク Více turist T neǵ ve stejném období roku 2012 navğívilo pouze 5 ze 14 kraj丁 ḶR, pŚ| emǵ nejvíce to bylo stejnクjako $\mathrm{v}$ pŚpadク délky pobytu $\mathrm{v}$ Olomouckém (o 7,3 \%) a Zlínském kraji (o 7,2 \%). Nejvhğ pokles byl v západních Ḷechách, kde do PlzeŔského kraje pŚjelo o 13,2 \% ménクhost丁 neǵloni.

Nejvíce zahranil ních host丁 pŚjelo v 2. | tvrtletí 2013 do Moravskoslezského kraje z Polska (více neǵ 6,2 tis., coǵ je pŚs $16 \%$ ze vğech nerezidentT, meziroḷ ní nárTst o více neǵ $20 \%$ ) a odsunuli tak na druhé místo tradil nクnejvクğ skupinu turist丁 ze Slovenska. Thh dorazilo pŚs 5,5 tis. pŚ mírném mezirol ním zvýǵení o $0,8 \%$. TŚetí a !̣t tvrté místo si, vzhledem k rozdílnému vývoji mezirol ního

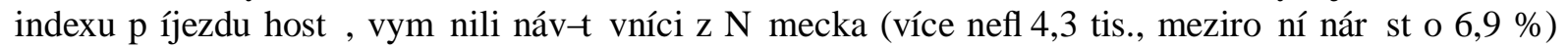
a Ruska (pŚs 4,1 tis., pokles o 7,4 \%). HostT z dalğ́ch státT jiǵ bylo podstatnクmén円ï více neǵ tisíc jich do Moravskoslezského kraje dorazilo z Itálie, Spojených stát丁 amerických a Rakouska.

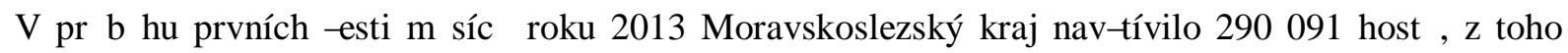
tém战 $22 \%$ bylo ze zahranil í. Celkový pol et host丁 se tak mezirol nךsnígil o $0,3 \%$, a to zásluhou domácích turist T (pokles o 1,1\%), Zahranil ních hostT dorazilo o 2,9\% více neǵ ve stejném období p\$́dchozího roku. Z regionálního srovnání vyplývá, ǵe nejvíce host T smగśovalo do Hlavního $\mathrm{m} h$ ta

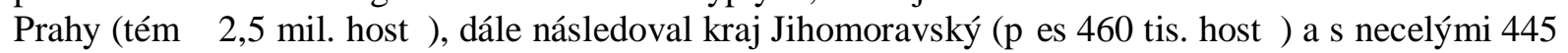
tis. hostT Královéhradecký kraj. PŚ́znivé výsledky, tj. meziroḷ ní pŚrTstek pol tu hostT, vykazuje 8 kraj丁, pŚ| emǵ nejvyğǵch pŚrTstkT dosáhly kraje Pardubický (o 6,5\%) a Liberecký (o 5,0 \%). Nejviğ pokles zaznamenal PlzeRksý kraj, kam pŚjelo o 8,6 \% ménクhostT neǵloni.

\subsection{SWOT analýza Moravskoslezského kraje}

Analýza SWOT je prvním krokem k ur! ení souḷasné pozice destinace na trhu cestovního ruchu. Ur!̣ ení silných a slabých stránek destinace zjistíme, z l़ eho se skládá nabídka destinace na trhu cestovního ruchu a rozeznáním pŚleğitostí a ohroǵení nabídky destinace na trhu zjistíme, co ovlivŔuje úsplğnost nabídky destinace na trhu a v jakém smクju. Správná analýza silných stránek a jejich následné vyugoití je pŚedpokladem úspḩhu nabídky dané destinace na trhu cestovního ruchu a úspłğgého vytvoŚní marketingové strategie. Pro tvorbu úsprọné marketingové strategie je dTleğité odhalit taktéǵ slabé stránky a tím i moǵností jak je následnクeliminovat. Analýza silných a slabých stránek je i analýzou linností a trendT v rámci destinace. Posuzují se z hlediska jiǵ dosaǵených výsledkT i dalğ́ch potencionálních moǵností realizace produktu na trhu. Dále pŚleǵitosti destinace na trhu cestovního ruchu pŚdstavují nejen výhody vyplívající ze silných stránek, ale i výhody vyplívající z vnクğho prostŚedí destinace, v pŚpadn ğe je moğné je vyuğ́t. Ohroǵení destinace obvykle vyplývá ze slabých stránek, resp. z nevýhod v rámci vnクğho prostŚedí jako jsou napŚklad sm円nné kurzy, stoupající cena ropy a jiné (Rýglová et al. 2011).

\section{SWOT analýza Moravskoslezského kraje ï zam任í na cestovní ruch.}

\section{Silné stránky}

- Významný pŚrodní potenciál a pŚrodní prostŚ́dí.

- Na vクğnク území se nachází lokality se statusem pŚrodních rezervací, národních pŚrodních rezervací a památek.

- Bohaté zázemí historicko ï kulturních památek.

- Blízkost letných hranil ních pŚcchodT s Polskem a Slovenskem, snadný pŚstup návğ円yníku ze sousedních zemí.

- Znal ná lást regionu je tvoŚna zalesn円ými plochami.

- Moǵnost celorol ního vyugóíí oblasti.

- Velké mnoğství lyğaŚských areálT a brğeckých tratí v zimních mḩících.

- Velké mnoğ́ství zaŚzení pro relax a wellness.

- Lokalita s vhodnými podmínkami pro ǵivol ig̉nou výrobu a pastevectví.

- Dobrá cenová dostupnost sluǵeb cestovního ruchu. 
Slabé stránky

- Dopravní dostupnost n nterých turistických atraktivit a nekvalitní silnil ní znal ení.

- Gatná kvalita místních komunikací.

- Nedostatek parkovacích míst.

- Nekvalitní ubytovací zaŚzení v nhkterých lokalitách.

- Nedostatel ná propagace oblasti.

- Nízká nabídka sluǵeb cestovních kanceláŚ.

- Nízká návğßynost ze strany zahranil ních turistT.

- Nedostatel ná podpora finan! ních prostŚdku.

- Nedostatek pracovních míst pro lerstvé absolventy.

- Dostatek restaurací nabízejících regionální speciality.

\section{PŚleǵitosti}

- Dalğ rozvoj turisticky atraktivních lokalit.

- Rozvoj a modernizace lyğaŚsých st ́́́disek.

- Rozǵśní zahranil ní klientely.

- Propagace pŚznivé cenové nabídky.

- Podpora nových forem turismu (agroturistika, ekoturistika).

- Vyuǵití nových forem propagace.

- Vyuǵivaní trvale udróitelného rozvoje k podpoŚ konkurence schopnosti.

- Moǵnost le erpání národních a mezinárodních podpTrných programT, dotací.

- Rostoucí zájem o domácí turistiku.

\section{Hrozby}

- Nedostatek finan! ních zdrojT pro opravy a modernizace oblasti.

- Zhorǵování stavu silnic a cest.

- Neúl inná marketingová strategie.

- Stagnace zlepǵování kvality sluǵeb v zaŚzeních ur! ených pro cestovní ruch.

- PŚtíǵ́ní nejvýznamnクğch turistických lokalit v zimním období (Mosty u Jablunkova, Bílá).

- Nízká konkurenceschopnost nクterých ménךatraktivních lokalit.

- Blízkost a sílící pozice a rozvoj konkuren! ních regionT.

Na základクSWOT analýzy mTǵeme p§́dpokládat, ǵe podpora rozvoje regionální gastronomie je dobrou cestou k navýǵení turismu v oblasti. Dle portálu http://www.czechspecials.cz/restaurace/ jsou v MSK certifikované tyto restaurace: Beskydský Horizont, Kun! ice pod OndŚjníkem , Bowling City, Kojetín, Carbon, Frýdek ï Místek, Clarion Congress Hotel - Restaurace, Ostrava [23], Horský hotel Sepetná, Ostravice, Hotel Cvilín, Krnov, Hotel Jana, PŚrov, Hotel Pivovar, Kojetín, Hotel Sport, Orlová ï Lutynク Hotel Zámek, HavíŚv, Mamaison Hotel Imperial - Restaurace La Brasserie, Restaurant Legend, Ostrava, Miura hotel, L eladná, Penzion Bクa, Bクá pod Pradhlem, Potrefená Husa, Ostrava, Racek, Ostrava-Výǵkovice, Restaurace Golf Resort Lipiny, Karviná-Fryǵát, restaurace Lağká jizba, Sedlig̉n Restaurace La Vida, Ostrava, Restaurace Nelli, HavíŚv, Restaurace Srub, Ostrava ï Dubina, Restaurace U Helbicha, Ostrava ï ZábŚch, Restaurant Buena Vista, Ostrava ï ZábŚch, Restaurant Kaskáda, Ostrava, Sporthotel Kurzovní, Karlova Studánka, Výtopna, Orlová a Zajel ský vinný sklep, Ostrava- Maránské hory [11].

\section{Závif}

Na základク provedené regionální analýzy, která byla zamłśena na popis geografických, demografických a kulturních pŚedpokladT oblasti, mTǵeme hovoŚt o tom, ǵe Moravskoslezský kraj má pŚdpoklady pro rozvoj regionální gastronomie. Dalg̉ metodou pouǵitou v ḷ lánku je pak SWOT analýza. Ta poslouğila k ur! ení silných a slabých stránek regionu, jeho pŚleǵitostí a hrozeb. SWOT analýza byla zamfśna na cestovní ruch $\mathrm{v}$ oblasti. Regionální gastronomie je jednou z moǵností ke

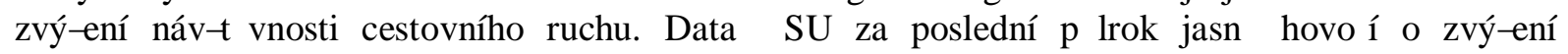
návg் hnosti. Lidé mají zájem o region a dobśs postavená strategie pro propagaci regionální gastronomie povede $\mathrm{k}$ dalğmu nárTstu turist $\rceil$. L lánek nepopisuje vg̉echny pŚedpoklady pro rozvoj této 
oblasti. Autor se bude touto problematikou i nadále hluboce zaobírat a dalğm cílem bude navrhnout regionální strategii pro podporu cestovního ruchu v oblasti se zamßśením právク na regionální gastronomii.

\section{Literatura}

[1] BOHÁL̦KOVÁ, I., HRABÁNKOVÁ, M., (2009). Strukturální politika EU. Praha: Beck. ISBN 978-807400-111-6.

[2] BOHM, A., (2008). The SWOT Analysis. GRIN Verlag. ISBN 978-3-640-42419-1.

[3] CzechTourism, (2014). Czech Specials, or Taste the Czech Republic!. [online]. [cit 1.4.2014]. Dostupné z: $<\mathrm{http}: / /$ www.czechspecials.cz/>.

[4] L̦eský statistický úŚd,, (2014a). Charakteristika Moravskoslezského kraje. [online]. [cit.18.3.2014]. Dostupné z: 〈http://www.czso.cz/xt/redakce.nsf/i/charakteristika_moravskoslezskeho_kraje〉.

[5] L Leský statistický úŚid, (2014b). Moravskoslezský kraj. [online]. [cit.18.3.2014]. Dostupné z: <http://www.czso.cz/csu/2012edicniplan.nsf/t/4C0020FF4C/\$File/80136412a1.pdf>.

[6] HAMPL, M., (1998). Výzkumné trendy v sociální geografii. Sborník Leské geografické spole! nosti, vol 103 , iss. 4, pp. 437-444.

[7] IVANIL,KA, K., (1998). Základy teórie a metodológie socioekonomickej geografie. Bratislava: SNP. p. 448.

[8] JAKUBíKOVÁ, D., (2012). Marketing v cestovním ruchu. Praha: Graha Publishing. ISBN 978-80-2474209-0.

[9] JAKUBÍKOVÁ, D., (2009). Strategický marketing. Praha: Graha Publishing. ISBN 978-80-247-2690-8.

[10] KRIZEK, F. , NEUFUS, J., (2011). Moderní hotelový management. Praha: Grada. ISBN 978-80-247$3868-0$.

[11] Moravskoslezský kraj, (2014). Gastronomické speciality. [online]. [cit.18.3.2014]. Dostupné z: $\langle$ http://www.msregion.cz/scripts/detail.php?pgid=350\&conn=1522\&pg=1>.

[12] RÝGLOVÁ, K. et al., (2011). Cestovní ruch Ï podnikatelské principy a pŚleǵtosti v praxi. Praha: Grada. ISBN 978-80-247-4039-3. 